\title{
Compounds Developed from the La-As-Fe System at High Temperature Chenlv Peng ${ }^{1, a}$, Jinzhu Zhang ${ }^{1, b}$ \\ ${ }^{1}$ College of Materials and Metallurgy, Guizhou University, Guiyang 550025, China

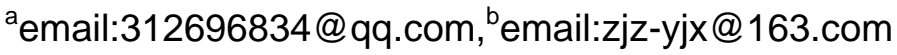

Keywords: Lanthanum; Arsenic; Fe2As; LaAs; La10Fe54As37

\begin{abstract}
The interaction among Lanthanum, Arsenic and Iron at high temperature in a pressure-tight reactor machined by $\mathrm{H} 08$ steel were studied by means of electron probe microanalysis, optical microscopy and X-ray diffraction to understand what compounds could be developed on the condition that the atomic ratio of La to As is 1:2. The result shows that the ternary compound $\mathrm{La}_{10} \mathrm{Fe}_{54} \mathrm{As}_{37}$ and the binary compound LaAs are the main interaction products at 1223 K. There are some Fe2As compounds developed meanwhile. Moreover, the eutectic compound $\mathrm{Fe}_{2}$ As can be precipitated from ferrite with the temperature decreasing.
\end{abstract}

\section{Introduction}

Arsenic in steel mainly segregated on grain boundary and it is probably that the impact toughness, the cold brittleness and the hot-working performance of steel would be deteriorated [1-4]. The arsenic in steel commonly come from a certain amount of iron ores but it is difficult to removal in the conventional ironmaking and steelmaking process, because its oxidation potential is lower than that of Iron. The rare earth metals, which have a stronger affinity with the deleterious impurities, such as the oxygen, sulfur, phosphorus and some low melting point metals contained in steel, are often used to purify the liquid steel [5]. According to the thermodynamic property in binary phase diagram, the compounds $\mathrm{Fe}_{2} \mathrm{As}$, FeAs and $\mathrm{FeAs} s_{2}$ can be developed in the $\mathrm{Fe}-\mathrm{La}$ system [6-7]. With a higher content of lanthanum in steel, the metastable phase $\mathrm{Fe}_{\mathrm{x}} \mathrm{La}_{1-\mathrm{x}}\left(0.65<\mathrm{X}_{\mathrm{Fe}}\right.$ $<0.9$ ) can be developed[8]. It was reported that the compounds LaAs and $\mathrm{LaAs}_{2}$ can be developed at $1023 \mathrm{~K}$ [9]. Moreover, it was reported if the La pieces, Fe powder, and As lumps in a molar ratio of 1:5:3 was placed in an evacuated fused-silica tube together with a 6-fold (by weight) excess of stannum, stepwise heated to $1173 \mathrm{~K}$ over 3 days, held at this temperature for 4 days, and slowly cooled $(4 \mathrm{~K} / \mathrm{h})$ to $873 \mathrm{~K}$, followed by furnace cooling to room temperature. The ternary arsenide $\mathrm{RE}_{12} \mathrm{Fe}_{57.5} \mathrm{As}_{41}$ and binary FeAs were obtained [10]. In addition, the ternary compound $\mathrm{La}_{10} \mathrm{Fe}_{50} \mathrm{As}_{40}$ was found from the La-As-Fe system at $1223 \mathrm{~K}$ [11] in a pressure-tight cylinder machined by H08 steel. In this study, a certain amount of rare earth metal lanthanum and low melting point arsenic were closed in the barrel-shaped cylinder machined by H08 steel, heated to $1223 \mathrm{~K}$ for $50 \mathrm{~h}$. Microstructure and compounds of the La-As-Fe system were studied by X-ray diffraction, optical microscopy, and electronic probe microscopy analysis.

\section{Experiment}

The sample preparation device like a pressure-tight cylinder is shown in figure 1 , and machined by H08 steel which the main composition is as follows: $0.35 \%$ (mass percent) Mn, $0.03 \%$ $\mathrm{Si}, 0.082 \% \mathrm{C}, 0.016 \% \mathrm{P}, 0.014 \% \mathrm{~S}$, and $99.3 \% \mathrm{Fe}$. The rare earth metal lanthanum pieces (purity 99.00\%) and the non-metal arsenic particles (purity 99.99\%) with the size below $5 \mathrm{~mm}$ are weighed according to the atomic ratio of La to As is 1:2, and put into the cylinder, then screwed down and welded the cylinder. There are $4.809 \mathrm{~g}$ La and $5.191 \mathrm{~g}$ As in the cylinder.

The cylinder was put into SRJK-2-9-tube vacuum resistance, and heated slowly in the reduction atmosphere as $\mathrm{H}_{2}: \mathrm{Ar}=1: 10$. The temperature was controlled based on the vapor pressure of As as follows: taking $2 \mathrm{~h}$ form room temperature to $773 \mathrm{~K}$; from $773 \mathrm{~K}$ to $923 \mathrm{~K}$, taking $10 \mathrm{~min}$ for increasing every ten degrees; from $923 \mathrm{~K}$ to $973 \mathrm{~K}$, taking $20 \mathrm{~min}$ for increasing every ten degrees; from $973 \mathrm{~K}$ to $1023 \mathrm{~K}$, taking 30 min for increasing every ten degrees; from $1023 \mathrm{~K}$ to $1073 \mathrm{~K}$, 
taking $1 \mathrm{~h}$ for increasing every ten degrees; from $1073 \mathrm{~K}$ to $1123 \mathrm{~K}$, taking $2 \mathrm{~h}$ for increasing every ten degrees; from $1123 \mathrm{~K}$ to $1173 \mathrm{~K}$, taking $3 \mathrm{~h}$ for increasing every ten degrees; from $1173 \mathrm{~K}$ to $1223 \mathrm{~K}$, taking $5 \mathrm{~h}$ for increasing every ten degrees, and keeping for $50 \mathrm{~h}$ at $1223 \mathrm{~K}$, followed by furnace cooling to room temperature and turned off the protective gas.

The sample was sawed off laterally about $16 \mathrm{~mm}$ away from the bottom by hand. One part of the sample was prepared for metallographic observation and electronic probe microscopy analysis. The other part was scratched and taken the central substance which was mainly developed from La, As, and Fe in the cylinder at high temperature processing. The substance from the internal infiltration layer scratched off was crushed, ground for X-ray diffraction analysis.
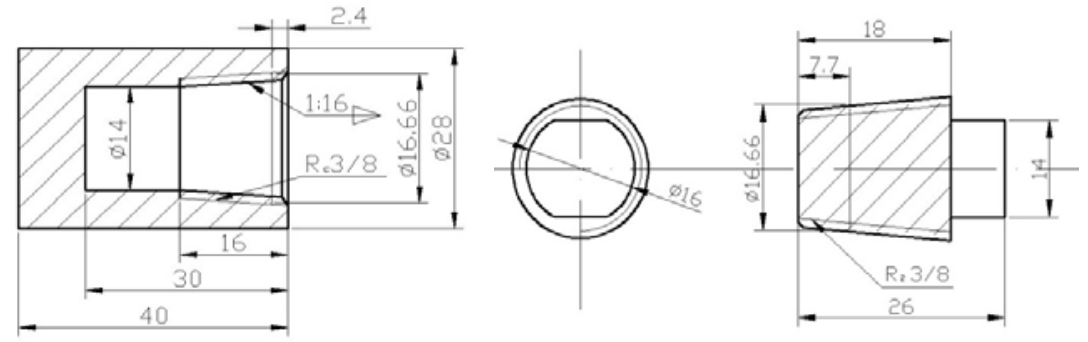

Fig.1. The diagram of the barrel-shaped cylinder and the screw plug

\section{Results and Discussions}

There are at least four different microstructures seen on the metallograph marked by a, b, c, and d (see Fig.2) or the backscattered electron image marked by A, B, C, and D (see Fig.3) in the sample. The compounds marked by A1, A2, and A3 show in light on the backscattered electron image but in dark gray marked by a on the metallograph. The phases labeled by B1, B2, and B3 show in light gray on the backscattered electron image and in gray marked by b on the metallograph. The microstructures indicated by C1, C2, and C3 show in dark gray on the backscattered electron image and in light gray indicated by c on the metallograph. The compounds labeled by D1, D2, and D3 show in gray on the backscattered electron image. The microstructure marked by d show in black on the metallograph, changed from the dark gray compounds by oxidized and scratched away.

The main chemical compositions on various microstructures are shown in table 1 that is determined by means of electron microprobe.

The compounds marked by A1, A2, and A3 are mainly composed by La and As (see table 1 and Fig.3), doped a few Fe atoms. The atomic ratio of La to As is approximately 1:1. Based on the results determined by X-ray diffraction, this phase has a LaAs crystal structure (see fig.4).

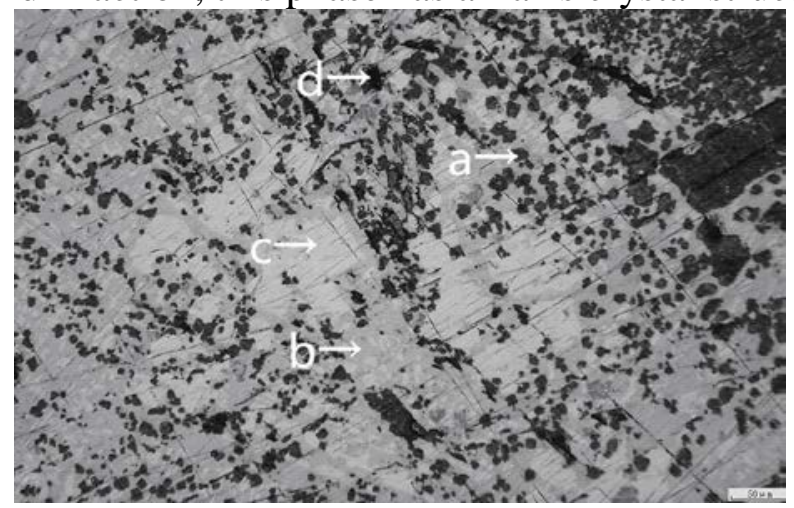

Fig.2 Metallograph of the central area of sample 


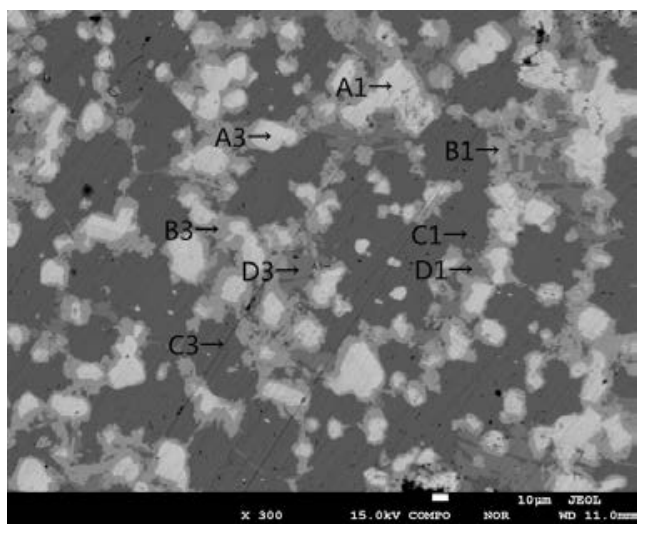

central area

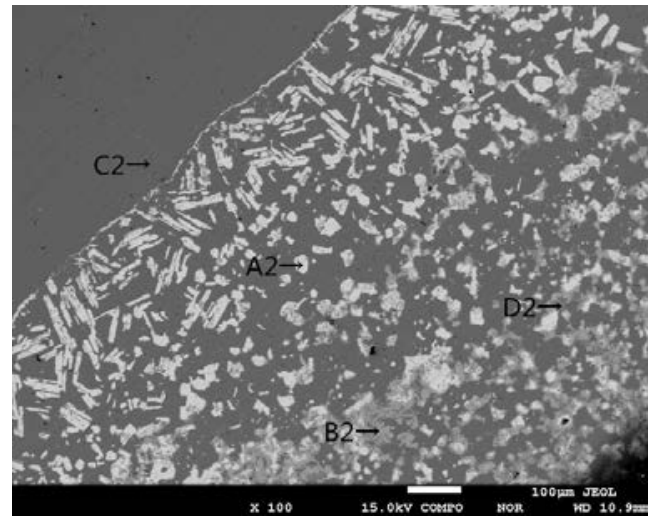

the area closes to the cylinder

Fig.3 Backscattered electron image of the sample

The compounds marked by D1, D2, and D3 are mainly composed by Fe and As besides a little La (see table 1 and Fig.3). The atomic ratio of Fe to As is approximately 2:1. Based on the results determined by X-ray diffraction, this phase has a Fe2As crystal structure (see fig.4).

The phases labeled by B1, B2, and B3 are mainly composed by Fe, La and As, (see table 1 and Fig.3). There is a small difference among the molar ratios of Fe, La and As. Comparing with the ternary arsenide La10Fe50As40 (the atomic ratio of La to As is 1:3) [11], it could be written as La9.74Fe52.69As37.57, La9.83Fe52.46As37.75, and La9.95Fe52.98As37.06, respectively by the composition of the phases labeled by B1, B2, and B3 according to the stoichiometric. The lower arsenic content in the ternary arsenide may be related with the lower atomic ratio of As to La in this study compared with that in literature [11]. Based on the results determined by X-ray diffraction (see fig.4), there are some diffraction lines identified as RE12Fe57.5As41 [10]. It is shown that the La9.84Fe52.71As37.46 (take mean value) has a similar or same crystal structure with the Ce12Fe57.5As41 [10]. If the ternary compound is developed from the binary compounds LaAs and Fe2As by a reaction, it might be written as: 10LaAs+27Fe2As= La10Fe54As37. The X-ray diffraction patterns for ternary compounds La-Fe-As might have not been reported. Moreover, these gray compounds show the characteristics of homogeneous phase both on the metallograph and the backscattered electron image of the sample. Therefore, these light gray phase may be a ternary arsenide as the La10Fe54As37 with an alterable composition in a certain range.

The microstructures indicated by C1, and C3 are mainly composed by Fe and As besides a little La (see table 1 and Fig.3). Based on both the results determined by X-ray diffraction(see fig.4), and the phase diagram of the Fe-As system, it can be seen that As dissolved in ferrite of iron saturated at high temperature, and the eutectic compound Fe2As may be precipitated from ferrite with the temperature decreasing. The microstructure indicated by $\mathrm{C} 2$ is the base of the cylinder machined by H08 steel. It is also composed by Fe and As as well as the microstructures indicated by C1, and C3. Therefore, the microstructure indicated by C2 should be ferrite and Fe2As. It can be seen that As dissolved in ferrite of iron by diffusion at high temperature.

There are no any binary compounds composed by La and Fe being detected by this experiment. It could be thought that the element La react selectively with As rather than Fe. In other words, there is a stronger interaction between $\mathrm{La}$ and As than between La and Fe.

\section{Conclusions}

The ternary arsenide La10Fe54As37 with an alterable composition in a certain range can be developed in the sample at $1223 \mathrm{~K}$.

The binary compound LaAs and the ternary compound La10Fe54As37 are the main interaction products at $1223 \mathrm{~K}$ in the La-As-Fe system when the atomic ratio of La to As is 1:2. There are some binary compound Fe2As developed meanwhile.

The eutectic compound Fe2As can be precipitated from ferrite in which there is a high content as dissolved at high temperature with the temperature decreasing. 
Table.1 Atomic ratio of element for different microstructures analyzed by electron probe (At\%)

\begin{tabular}{cccccccc}
\hline Sit & La & $\mathrm{Fe}$ & $\mathrm{As}$ & $\mathrm{Sit}$ & $\mathrm{La}$ & $\mathrm{Fe}$ & $\mathrm{As}$ \\
\hline $\mathrm{A} 1$ & 48.4898 & 1.9644 & 49.5458 & $\mathrm{C} 1$ & 0.2866 & 90.9800 & 8.7335 \\
$\mathrm{~A} 2$ & 46.5139 & 1.5954 & 51.8907 & $\mathrm{C} 2$ & 0.1484 & 90.9441 & 8.9075 \\
$\mathrm{~A} 3$ & 47.8368 & 6.2327 & 45.9305 & $\mathrm{C} 3$ & 0.1538 & 91.4543 & 8.3919 \\
B1 & 9.7370 & 52.6926 & 37.5704 & $\mathrm{D} 1$ & 0.4508 & 65.9366 & 33.6126 \\
B2 & 9.8270 & 52.4558 & 37.7472 & $\mathrm{D} 2$ & 0.2775 & 65.2859 & 34.4366 \\
B3 & 9.9539 & 52.9886 & 37.0575 & $\mathrm{D} 3$ & 0.3117 & 65.5911 & 34.0972 \\
\hline
\end{tabular}

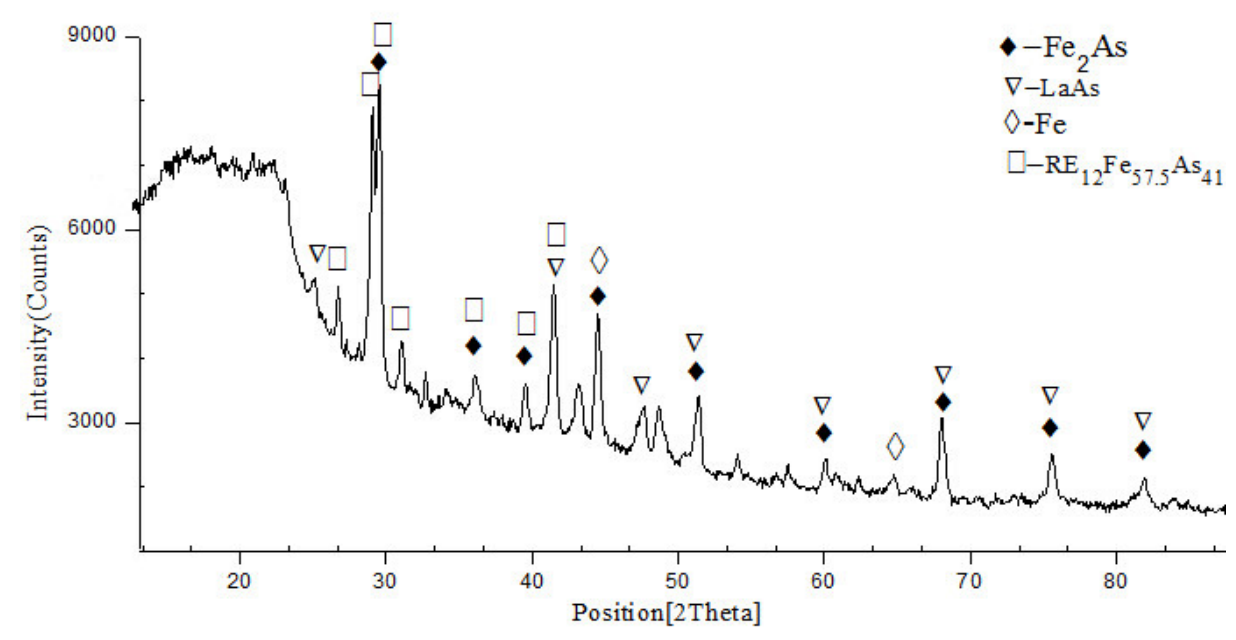

Fig.4. X-ray diffraction pattern of the sample

\section{Acknowledgment}

The authors gratefully acknowledge the financial support provided by National Natural Science Foundation of China (50964002).

\section{References}

[1] Liu Shouping and Sun Shanchang A Study on Dearsenication of Molten Iron and Liquid Steel with Ca-Si Alloy [J]. Special Steel, 2001, 22(5): 12-15.

[2] Zhi Guorui, Liu Jihong, Ma Hongyan, Wang Yanli, Shi Xiaofeng Direct Determination ofArsenic, Antimony and Tin in Steel by ICP-AES [J]. Chinese Journal of Spectroscopy Laboratory,2002, 19(4): 485-487.

[3] Feng Zan and Xiao Jiguang Effect of As and La on continuous cooling transformation curve of E36 ship hull steel [J]. Heat Treatment of Metals, 2009, 34(3): 14-17.

[4] Ni Jun The Impact of Arsenic on Mechanical Properties and Microstructure in 9Cr2Mo Steel [J]. Modern Metallurgy, 2009, 37(3):30-32.

[5] Li Chunlong. Some Suggestions on Application of Rare Earth in Steel [J]. Chinese Rare Earths, 2001, 22(4): 1-6.

[6] W. F. Gale\&T. C. Totemeir Smithells Metals Reference Book [M]. Boston: Butterworth-Heinemann, 2004: 497.

[7] Yin Guojin The Distribution of Arsenic in Steel [J]. Iron \& Steel, 1981, 16(2): 20-28.

[8] W.Zhang and C.Li The Fe-La(Iron-Lanthanum) System [J]. Journal of Phase Equilibria, 1997, 
18: 301.

[9] F. Hulliger and B.Natterer Low-Temperature Specific Heat of Erbium Pnictides [J],Solid State Commun.1973,13,221.

[10] Stanislav S. Stoyko, Peter E. R. Blanchard, and Arthur Mar Ternary Rare-Earth Iron Arsenides $\mathrm{RE}_{12} \mathrm{Fe}_{57.5} \mathrm{As}_{41}(\mathrm{RE}=\mathrm{La}, \mathrm{Ce})$ [J]. Inorganic Chemistry, 2010, 49: 2325-2333.

[11]. Xiaodong Liu, Jinzhu Zhang, Sisi Zhu Microstructure and Compound Developed from La-As-Fe System at 1223K [J]. Advanced Materials Research, 2013, 702: 145-148. 